\title{
ROLE OF VON WILLEBRAND FACTOR IN TYPE 2 DIABETES MELLITUS PATIENTS
}

\author{
Umadevi B', Roopakala M. S2, Wilma Delphine Silvia C. R3, Prasanna Kumar K. M4
}

${ }^{1}$ Assistant Professor, Department of Physiology, Sapthagiri Institute of Medical Sciences and Research Centre, Bangalore. 2 Professor and HOD, Department of Physiology, M. S. Ramaiah Medical College, Bangalore.

3 Professor and HOD, Department of Biochemistry, Akash Institute of Medical Sciences and Research Centre, Bangalore. ${ }^{4}$ Professor, Department of General Medicine (Endocrinology), M. S. Ramaiah Medical College, Bangalore.

\section{ABSTRACT}

\section{BACKGROUND}

Endothelial dysfunction is the main cause of morbidity and mortality in diabetic patients. Endothelial dysfunction has been incriminated in the early pathogenesis of atherosclerosis and is considered an early indicator of cardiovascular disease by dysregulation of vascular tone, growth, thrombogenicity, inflammation and the development of both micro- and macro-vascular disease states. Von Willebrand factor is a well-known marker of endothelial dysfunction. The objective of this study is to measure plasma levels of von Willebrand factor in type $2 \mathrm{DM}$ patients and to compare with the normal subjects. Urinary albumin levels, which is also a marker of generalised endothelial dysfunction and a strong predictor for the development of both micro- and macro-vascular disease was also assessed in the two groups and its association with von Willebrand factor (vWF) was studied.

\section{MATERIALS AND METHODS}

In this cross-sectional study, twenty-five type 2 diabetic patients (45-60 years) with duration of diabetes between 5-10 years and twenty-five age and sex matched healthy volunteers were considered. Plasma von Willebrand factor (vWF) and urine albumin levels were measured, Student ' $t$ ' test and Pearson correlation was used to analyse the data.

\section{RESULTS}

Mean levels of vWF were significantly increased $\left(\mathrm{P}<0.001^{* *}\right)$ in type 2 Diabetic patients compared to normal. Mean value of urinary albumin levels was higher in those with $\mathrm{DM}$ compared to the normal $\left(\mathrm{P}<0.001^{* *}\right)$.

\section{CONCLUSION}

The present study suggests that there is significant endothelial injury in type 2 DM patients and they are probably at risk of developing cardiovascular disease in the future. vWF and urinary albumin levels showed a weak correlation in type 2 DM patients, which might support the view that they are under substantially different regulatory control.

\section{KEYWORDS}

Von Willebrand Factor (vWF), Microalbuminuria, Endothelial Dysfunction, Atherosclerosis, Cardiovascular Disease.

HOW TO CITE THIS ARTICLE: Umadevi B, Roopkala MS, Silvia WDCR, et al. Role of von Willebrand factor in type 2 diabetes mellitus patients. J. Evolution Med. Dent. Sci. 2016;5(81):6075-6079, DOI: 10.14260/jemds/2016/1372

\section{BACKGROUND}

Diabetes is a common metabolic disorder characterised by fasting hyperglycaemia and the development of chronic vascular complications. The prevalence of type 2 diabetes has tripled in the past 15 years in association with obesity. Recent evidence has established type 2 diabetes mellitus as a potent cardiovascular risk factor with annual mean mortality rate of $5.4 \%{ }^{1,2}$ Men with diabetes have two-fold to three-fold increase in Coronary Artery Disease (CAD) compared with non-diabetics. ${ }^{3}$ It affects between $1 \%$ and $10 \%$ of most population, although in some areas of the world up to $50 \%$ of the population has diabetes. 4 Most recent studies have projected that by 2030 India will have 79-87 million adults with diabetes. ${ }^{5}$ It has been known for many years that the development of diabetes mellitus is associated with increased

Financial or Other, Competing Interest: None.

Submission 16-09-2016, Peer Review 29-09-2016,

Acceptance 01-10-2016, Published 10-10-2016.

Corresponding Author:

Umadevi $B$,

No. 167, Sapthagiri, ISEC Main Road,

Nagarabhavi Village,

Bangalore-560072.

E-mail: documa2001@rediffmail.com

DOI: $10.14260 /$ jemds $/ 2016 / 1372$

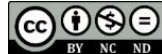

risk for cardiovascular, cerebrovascular and peripheral vascular disease. Patients with type 2 diabetes have early development of abnormal endothelial function, platelet hyperactivity, aggressive atherosclerosis, a propensity for adverse arterial remodelling, enhanced cellular and matrix proliferation after arterial injury and impaired fibrinolysis with a tendency for thrombosis and inflammation. As a result, the diabetic state leads to profound arteriopathy; perhaps the earliest demonstrable manifestation is that of endothelial dysfunction. ${ }^{6}$

Vascular endothelium is not just a cell lining, it serves as a physical barrier between the lumen and the vessel wall. It also provides a smooth non-thrombogenic surface and plays an active role via various mediators in the equilibrium of haemostasis and fibrinolysis, regulation of vessel tone and permeability as well as synthesis of growth factors.7,8,9 Endothelial dysfunction is known to occur in type 2 Diabetes Mellitus (DM), which plays a critical role in the development of atherosclerosis, a process that occurs prematurely and at an accelerated rate in diabetic patients.10,11,12 Vascular endothelium damage is characterised by an increase in the plasma levels of endothelial markers like von Willebrand factor (vWF), Cellular Adhesion Molecules (CAD), endothelin 1 (ET1), plasminogen 1 activator inhibitor type-1 (PAI-1), selectin, thrombomodulin. These markers may be useful to 
investigate early endothelium involvement. An increased level of von Willebrand factor ( $\mathrm{vWF}$ ) reflects activation and damage to endothelial cells and has been described in association with atherosclerosis and diabetes. High concentration levels of von Willebrand factor (vWF) have been detected in certain inflammatory or atherosclerotic vascular incidents and indicate a deterioration of endothelial cells.13,14,15,16,17

In patients with type 2 diabetes, microalbuminuria is also associated with an increase in cardiovascular mortality. Microalbuminuria signals the presence of an atherogenic milieu because of its association with several risk factors for atherosclerosis. Microalbuminuria also represents early generalised vascular (endothelial) damage.18,19,20 Von Willebrand factor ( $\mathrm{vWF}$ ) appears to be a predictive marker of diabetic nephropathy, which suggests that endothelial dysfunction precedes the onset of diabetic microangiopathy. Von Willebrand factor (vWF) expression as well as their possible association with different metabolic abnormalities present in diabetes remains poorly explained. Therefore, the aim of this study was to assess endothelial function by measuring plasma levels of vWF and urine albumin levels in type 2 diabetes mellitus patients and in the normal subjects.

Our study was a comparative study of 50 subjects in the age group of 45-60 years in which 25 previously diagnosed type $2 \mathrm{DM}$ patients were recruited from those attending the outpatient department of Endocrinology at M. S. Ramaiah Medical College and Teaching Hospital, Bangalore; 25 healthy age and sex matched normal subjects were recruited by history, questionnaire and by clinical examination from the general population.

\section{Inclusion and Exclusion Criteria}

Type 2 DM patients diagnosed as per WHO criteria with the duration of diabetes 5-10 years and non-smokers. Patients with Hypertension, Renal impairment, Previous vascular events (angina, myocardial infarction, acute arterial occlusion), Autoimmune disorders, Cerebrovascular disease, Acute respiratory failure and $\mathrm{BMI}>30$ were excluded from the study. Ethical clearance was obtained from the M. S. Ramaiah Medical College Ethical Committee for human research to conduct the study. Subjects were recruited and examined from those attending the OPD at M. S. Ramaiah Memorial and Teaching Hospital.

Subjects were assigned into two groups: Group A - Controls (Normal subjects) and Group B - Cases (Type 2 DM patients). Subjects were screened for general physical health to rule out any clinical disorder likely to interfere with the study findings. Anthropometric measurements like weight in kilograms, height (to the nearest $\mathrm{cm}$ ) were recorded from all subjects. Body Mass Index (BMI) was calculated by the formula weight $(\mathrm{kg}) /$ height square $(\mathrm{m} 2)$. An informed written consent was obtained from all the study subjects after explaining the procedure. Parameters used for comparison were BMI, Blood pressure, FBS, PPBS, von Willebrand factor (vWF) and Urine albumin levels $5 \mathrm{~mL}$ of venous blood was collected from each study subject after a 12-hour overnight fast, using vacutainers and disposable needles after taking the necessary aseptic precautions from the antecubital vein. The vacutainers used were commercially available vacutainers containing 0.11 $\mathrm{mol} / \mathrm{mL}$ of trisodium citrate anticoagulant. After collecting the blood samples were immediately centrifuged at 2500 rotations/min for 10 mins. to obtain platelet poor plasma, carried out within 30 minutes following collection, after centrifugation the plasma was stored at $-20^{\circ} \mathrm{C}$ in Eppendorf tubes till the analysis was conducted. Fasting plasma glucose was determined by glucose oxidase method using glucose autoanalyser, von Willebrand factor was measured by Enzyme-Linked Fluorescent Assay (ELFA) method an automated quantitative test done on the mini VIDAS instrument (Biomerieux SA France). Urine albumin levels were measured by turbidimetric immunoassay (ERBA Mannheim GmbH, Germany) in all subjects.

\section{STATISTICAL ANALYSIS}

Software SPSS 15.0, Stata 8.0, MedCalc 9.0.1 and Systat 11.0 were used for analysis of the data. Descriptive statistical analysis has been carried out in the present study. Results on continuous measurements are presented on Mean \pm SD (MinMax) and results on categorical measurements are presented in number (\%). Significance is assessed at 5\% level of significance.

Student ' $\mathrm{t}$ ' test (two tailed, independent) has been used to find the significance of study parameters on continuous scale between two groups Intergroup analysis. Chi-square/Fisher Exact test has been used to find the significance of study parameters on categorical scale between two groups. Student ' $\mathrm{t}$ ' test (two tailed; independent) has been used to test the homogeneity samples based on age (or continuous parameters) and Chi-square test to test the homogeneity of samples based on parameters on categorical scale between two groups. Effect size has been computed to find the effect of Type II DM on vWF and microalbuminuria.

\section{RESULTS}

This comparative study consisted of 25 type 2 DM patients and 25 age, sex matched normal individuals in the age group of 45-60 years. The plasma vWF and urine albumin levels were compared between the normal and type $2 \mathrm{DM}$ patients. Also, the association of plasma vWF and urine albumin levels was studied in normal and type $2 \mathrm{DM}$ patients. Comparison of basic characteristics like age, gender, height, weight and BMI between two groups did not show significant difference ( $p>$ 0.05). The two groups were similar in terms of the basic characteristics as shown in Table 1. Patients with type 2 DM had higher systolic blood pressure $(131.52 \pm 8.55 \mathrm{mmHg}, \mathrm{P}=$ $0.002^{* *}$ ), although within the normal range than the individuals in the control group $(124.00 \pm 7.66 \mathrm{mmHg}), \mathrm{FBS}$ and PPBS were significantly higher in patients with type 2 DM (165.33 $\pm 46.38 \mathrm{mg} / \mathrm{dL}$ and $247.11 \pm 90.09 \mathrm{mg} / \mathrm{dL} \mathrm{P}<0.001^{* *}$ ) when compared with the control group $(74.00 \pm 7.21 \mathrm{mg} / \mathrm{dL}$ and $98.56 \pm 4.39 \mathrm{mg} / \mathrm{dL}$ ). Mean duration of diabetes was 10.3 years.

\begin{tabular}{|c|c|c|c|}
\hline Variables & Controls & Cases & P-value \\
\hline Height (mts) & $154 \pm 0.06$ & $154 \pm 0.08$ & 0.824 \\
\hline Weight (kg) & $61.32 \pm 9.83$ & $60.52 \pm 9.06$ & 0.766 \\
\hline BMI (kg/m2) & $25.92 \pm 3.35$ & $25.41 \pm 2.69$ & 0.558 \\
\hline Systolic BP & $124.00 \pm 7.66$ & $131.52 \pm 8.55$ & $0.002^{* *}$ \\
\hline Diastolic BP & $76.40 \pm 7.81$ & $76.56 \pm 6.36$ & 0.937 \\
\hline FBS (mg/dL) & $\begin{array}{c}74.00 \pm 7.21 \\
(55-85)\end{array}$ & $\begin{array}{c}165.33 \pm 46.38 \\
(98-321)\end{array}$ & $<0.001^{* *}$ \\
\hline PPBS (mg/dL) & $\begin{array}{c}98.56 \pm 4.39 \\
(89-105)\end{array}$ & $\begin{array}{c}247.11 \pm 90.09 \\
(144-567)\end{array}$ & $<0.001^{* *}$ \\
\hline \multicolumn{4}{|c|}{ Table 1: Comparison of Height, Weight, BMI, BP, FBS } \\
\hline \multicolumn{4}{|c|}{ and PPS in Cases and Controls } \\
\hline
\end{tabular}




\begin{tabular}{|c|c|c|}
\hline $\begin{array}{c}\text { Von Willebrand } \\
\text { Factor (vWF IU/mL) }\end{array}$ & Controls & Cases \\
\hline Min-Max & $0.16-1.04$ & $0.70-1.20$ \\
\hline Mean \pm SD & $0.57 \pm 0.25$ & $0.99 \pm 0.18$ \\
\hline $95 \% \mathrm{CI}$ & $0.47-0.67$ & 0.91-1.07 \\
\hline Inference & \multicolumn{2}{|c|}{$\begin{array}{c}\text { Levels of vWF is significantly } \\
\text { increased in cases with student } \\
\mathrm{t}=6.765 ; \mathrm{P}<0.001^{* *} \text { and very } \\
\text { large effect of } 1.89\end{array}$} \\
\hline $\begin{array}{l}\text { Table 2: Leve } \\
\quad(\mathrm{vWF} \text { IU } / \mathrm{m}\end{array}$ & $\begin{array}{l}\text { f Von Willebr } \\
\text { in Controls a }\end{array}$ & $\begin{array}{l}\text { ictor } \\
\text { es }\end{array}$ \\
\hline
\end{tabular}

\begin{tabular}{|c|c|c|}
\hline $\begin{array}{c}\text { Urine Albumin } \\
\text { (mg/L) }\end{array}$ & Controls & Cases \\
\hline Min-Max & $11.0-30.0$ & $33.0-123.0$ \\
\hline Mean \pm SD & $21.28 \pm 5.55$ & $73.20 \pm 20.03$ \\
\hline $95 \% \mathrm{CI}$ & $\begin{array}{c}18.98- \\
23.57\end{array}$ & $64.93-81.47$ \\
\hline \multicolumn{2}{|c|}{$\begin{array}{c}\text { Levels of Urine Albumin (mg/L) is } \\
\text { significantly increased in cases with } \\
\text { student t=12.485; P<0.001** and very } \\
\text { large effect of 3.45 }\end{array}$} \\
\hline \multicolumn{2}{|c|}{$\begin{array}{c}\text { Table 3: Levels of Urine Albumin (mg/L) } \\
\text { in Controls and Cases }\end{array}$} \\
\hline
\end{tabular}

\begin{tabular}{|c|c|c|c|c|}
\hline \multirow{2}{*}{ Pair } & \multicolumn{2}{|c|}{ Controls } & \multicolumn{2}{c|}{ Cases } \\
\cline { 2 - 5 } & $\begin{array}{c}\mathbf{p} \\
\text { value }\end{array}$ & $\begin{array}{c}\mathbf{p} \\
\text { value }\end{array}$ & $\begin{array}{c}\mathbf{r} \\
\text { value }\end{array}$ & $\begin{array}{c}\mathbf{p} \\
\text { value }\end{array}$ \\
\hline Age vs vWF & -0.161 & 0.441 & 0.114 & 0.556 \\
\hline BMI vs vWF & 0.023 & 0.921 & 0.231 & 0.266 \\
\hline Duration vs vWF & - & - & 0.104 & 0.620 \\
\hline $\begin{array}{c}\text { Urine albumin vs } \\
\text { vWF }\end{array}$ & 0.212 & 0.310 & -0.245 & 0.237 \\
\hline \multicolumn{3}{|c|}{ Table 4: Pearson Correlation } \\
(Age, BMI, Duration, Urine Albumin vs vWF) \\
\hline
\end{tabular}

Von Willebrand factor (vWF) levels were significantly higher in patients with type $2 \mathrm{DM}(0.99 \pm 0.18 \mathrm{IU} / \mathrm{mL}, \mathrm{P}<$ $\left.0.001^{* *}\right)$ when compared with the control subjects $(0.57 \pm 0.25$ $\mathrm{IU} / \mathrm{mL}$ ) as shown in Table 2 . Mean value of urine albumin levels was higher in patients with type 2 DM $(73.20 \pm 20.03$ $\mathrm{mg} / \mathrm{L}, \mathrm{P}<0.001^{* *}$ ) when compared with the control group $(21.28 \pm 5.55 \mathrm{mg} / \mathrm{L})$ as shown in Table 3. VWF and urinary albumin levels showed a weak correlation in type 2 DM patients ( $\mathrm{r}=-0.245, \mathrm{p}=0.237)$, but such correlation was not found in normal subjects $(r=0.212, p=0.310)$ as shown in Table 4.

\section{DISCUSSION}

Endothelial dysfunction may precede the development of atherosclerosis in the presence of different risk factor conditions. The increasing knowledge regarding how and how soon the endothelium can be injured and the release of a large variety of biologic markers has recently led to the assumption that these markers can be a surrogate for endothelial dysfunction.21,22 Vascular endothelium damage is characterised by an increase of endothelium-derived regulatory proteins. Plasma markers of endothelial dysfunction like von Willebrand factor (vWF), cellular adhesion molecules (CAD), endothelin 1 (ET1), selectin, thrombomodulin may be useful to investigate early endothelium involvement. Von Willebrand factor is thought to be more specific for endothelial dysfunction. The primary physiologic function of $\mathrm{vWF}$ is to maintain haemostatic balance in the vasculature, but because the endothelium is a primary source of vWF elevated levels reflect stimulation or injury to endothelial cells. It plays an important role in adhesion of platelets to the sub-endothelium and platelet aggregation, which are the initial stages in thrombus formation. $23,24,25$ In the present study, the two groups were similar in terms of the basic characteristics like age, sex, height, weight and BMI. The study characteristics like blood sugar, von Willebrand factor (vWF) and urine albumin levels showed a significant high values in type 2 diabetes mellitus patients when compared to normal $(\mathrm{P}<0.001)$.

This study supports the research hypothesis by the evidence of high levels of plasma vWF and high levels of urine albumin excretion and their weak correlation in type 2 diabetes mellitus patients when compared to normal.

In this study plasma von Willebrand factor (vWF) levels, a marker of atherosclerotic and atherothrombotic burden was significantly increased $\left(\mathrm{P}<0.001^{* *}\right)$ in type 2 diabetic patients compared to normal. This proves that there is endothelial dysfunction in type 2 DM patients. These findings are in agreement with those of James B. Meigs et al who concluded in their study that vWF to be more specific for endothelial dysfunction as it is secreted almost exclusively by endothelial cells and it is an independent precursor in type 2 DM. Thus, increased levels of von Willebrand factor (vWF) suggests significant endothelial injury, furthermore increased levels of vWF predicts cardiovascular morbidity and mortality. Possible mechanism could be because of hyperglycaemia, a potential glucose mediated mechanisms leading to increased oxidative stress, insulin resistance, inflammation mediated by cytokines, impaired NO production or it may be because of increased concentration of advanced glycation end products which can directly or indirectly induce endothelial dysfunction. ${ }^{26,27}$

Patient included in this study did not have diabetic complications or any other apparent risk factors like hypertension or smoking for endothelial damage apart from diabetes. Even though the selection process intended to include only patients with these characteristics, higher levels of systolic BP, although within normal range were observed in patients with diabetes, which could reflect the phenotypic characteristics of diabetes mellitus, probably because of the insulin resistance involved in diabetes. ${ }^{2} 8$

Microalbuminuria is generally regarded as a risk indicator rather than a risk factor and is a marker of widespread vascular damage and a predictor of progression of diabetic nephropathy is also powerful independent risk factor for coronary artery disease. ${ }^{20}$ Urine albumin levels, a strong predictor for endothelial damage were assessed and their correlations with von Willebrand factor (vWF) were studied in patients with type $2 \mathrm{DM}$ and normal subjects. Urine albumin levels were significantly increased $\left(\mathrm{P}<0.001^{* *}\right)$ in type $2 \mathrm{DM}$ patients compared to the normal. We therefore consider elevated levels of plasma vWF and urine albumin reflect underlying endothelial dysfunction. However, the weak correlation that we observed between the levels of these markers support the view that they are under substantially different regulatory control. These findings are consistent with those of James B. Meigs et al, Peter Gaede et al who also found a weak correlation with plasma vWF and microalbuminuria. ${ }^{26,28}$ The present study shows that type 2 DM patients have significant endothelial injury as assessed by increased levels of plasma von Willebrand factor (vWF) and urine albumin excretion. These patients are probably at risk of 
developing cardiovascular complications in the future. Therefore, early intervention is required to help these patients prevent future cardiovascular and renal complications.

\section{CONCLUSION}

The present study showed a significant increase in the plasma levels of von Willebrand factor (vWF) in patients with type 2 DM compared to normal, which suggests that there is significant endothelial injury in type 2 DM patients. Urine albumin levels were significantly increased in patients with type 2 DM compared to normal suggests that there is wide spread vascular damage. Further studies are required to monitor the rate of progression of albumin excretion to identify patients at risk for cardiovascular disease or decline in renal function. VWF the present findings can be confirmed in other populations; endothelial dysfunction/haemostatic dysfunction might represent a novel therapeutic target for prevention of CVD in people with type 2 diabetes mellitus or insulin resistance. The weak correlation observed between vWF and urine albumin levels suggest that they are under substantially different regulatory control.

\section{Scope for Further Studies}

Since this is a cross-sectional study we cannot conclude the exact mechanism of endothelial injury, therefore longitudinal studies need to be undertaken to prove this and also further studies are needed to find the relationship between endothelial injury markers and the inflammatory markers in type 2 DM patients.

\section{REFERENCES}

1. Storey AM, Perry CJ, Petrie JR. Endothelial dysfunction in type 2 diabetes. Br J Diabetes Vasc 2001;1(1):22-27.

2. Donnelly R, Emslie-Smith AM, Gardner ID, et al. Vascular complications of diabetes. BMJ 2000;320:1062-6.

3. Vaccaro 0, Stamler J, Neaton JD. Sixteen-year coronary mortality in black and white men with diabetes screened for the multiple risk factor intervention trial (MRFIT). Int J Epidemiol 1998;27(4):636-41.

4. Prevention of diabetes mellitus. Report of a WHO study group. World Health Organ Tech Rep Ser 1994;844:1-100.

5. Herman WH, Zmmet P. Type 2 diabetes: an epidemic requiring global attention and urgent action. Diabetes Care 2012;35(5):943-4.

6. Beckman JA, Creager MA, Libby P. Diabetes and atherosclerosis: epidemiology, pathophysiology, and management. JAMA 2002;287(19):2570-81.

7. Madhu SV. Endothelial dysfunction and diabetes. JAPI 2010;58:475-6.

8. Avogaro A, Albiero M, Menegazzo L. Endothelial dysfunction in diabetes: the role of reparatory mechanisms. Diabetes Care 2011;34(Suppl 2):S285-90.

9. Paez FG. Endothelial dysfunction and therapeutic intervention in type 2 diabetes. INTECH 2011. Available from: http://www.intechopen.com/books/medical complications-of-type-2-diabetes/endothelialdysfunction-and-therapeutic intervention-in-type-2diabetes.

10. Lee S, Park Y, Zhang C. Exercise training prevents coronary endothelial dysfunction in type 2 diabetes mice. Am J Biomed Sci 2011;3(4):241-52.
11. Kolluru GK, Bir SC, Kevil CG. Endothelial dysfunction and diabetes: effects on angiogenesis, vascular remodelling, and wound healing. Int J Vasc Med 2012;2012:1-30.

12. Ross R. The pathogenesis of atherosclerosis: a perspective for the 1990s. Nature 1993;362(6423):801-9.

13. Chong AY, Blann AD, Lip GYH. Assessment of endothelial damage and dysfunction: observations in relation to heart failure. Q J Med 2003;96:253-67.

14. Wannamethee SG, Sattar N, Rumley A, et al. Tissue plasminogen activator, von willebrand factor, and risk of type 2 diabetes in older men. Diabetes Care 2008;31(5):995-1000.

15. Laakso M. Cardiovascular disease in type 2 diabetes from population to man to mechanisms. Diabetes Care 2010;33(2):442-9.

16. Mannucci PM. von Willebrand factor: a marker of endothelial damage? Arterioscler Thromb Vasc Biol 1998;18(9):1359-62.

17. Hernestal-Boman J, Norberg M, Jan-Hakan J, et al. Signs of dysregulated fibrinolysis precede the development of type 2 diabetes mellitus in a population based study. Cardiovascular Diabetology 2012;11:152.

18. Thorand B, Baumert J, Chambless L, et al. Elevated markers of endothelial dysfunction predict type 2 diabetes mellitus in middle-aged men and women from general population. Arterioscler Thromb vasc Biol 2006;26(2):398-405.

19. Spoelstra-de Man AM, Brouwer CB, Stehouwer CD, et al. Rapid progression of albumin excretion is an independent predictor of cardiovascular mortality in patients with type 2 diabetes and microalbuminuria. Diabetes Care 2001;24(12):2097-101.

20. Samy N, Afify M, Majsood NAE. Circulating markers of endothelial dysfunction in type 2 diabetic patients with microalbuminuria. Asian Biomedicine 2012;6(2);175183.

21. Bonetti PO, Lerman LO, Lerman A. Endothelial dysfunction: a marker of atherosclerotic risk. Arterioscler Thromb Vasc Biol 2003;23(2):168-75.

22. Chen SF, Xia ZL, Han JJ, et al. Increased active von willebrand factor during disease development in the aging diabetic patient population. Age (Dordr) 2013;35(1):171-7.

23. Frankel DS, Meiqs JB, Massaro JM, et al. Von willebrand factor, type 2 diabetes mellitus, and risk of cardiovascular disease: the Framingham offspring study. Circulation 2008;118(24):2533-9.

24. Goldberg RB. Cytokine and cytokine-like inflammation markers, endothelial dysfunction and imbalanced coagulation in development of diabetes and its complications. J Clin Endocrinol Metab 2009;94(9):317182.

25. Tian J, Wang J, Li Y, et al. Endothelial function in patients with newly diagnosed type 2 diabetes receiving early intensive insulin therapy. American Journal of Hypertension 2012;25(12):1242-8.

26. Meigs JB. Epidemiology of type 2 diabetes and cardiovascular disease: translation from population to prevention: the Kelly West award lecture 2009. Diabetes Care 2010:33(8):1865-71. 
27. Li-hua L, Qiao-yan G, Chao-yuan L. Novel biomarkers for early diagnosis and progression of diabetic nephropathy. ARC Journal of Diabetes and Endocrinology 2015;1(1):1430 .
28. Seligman BG, Biolo A, Polanczyk CA, et al. Increased plasma levels of endothelin 1 and von willebrand factor in patients with type 2 diabetes and dyslipidemia. Diabetes Care 2000;23(9):1395-400. 